\title{
Correction to: The Effect of Tai Chi on Quality of Life in Centrally Obese Adults with Depression, by Liu X, Williams G, Kostner K, and Brown WJ. $J$ Altern Complement Med 2019;25(10):1005-1008. DOI: $10.1089 / \mathrm{acm} .2019 .0050$
}

n the October 2019 issue of The Journal of Alternative and Complementary Medicine (vol. 25, no. 10; 1005-1008), the article The Effect of Tai Chi on Quality of Life in Centrally Obese Adults with Depression by Liu et al. requires correction to its title and throughout the text.

The original title for this article read:

"The Effect of t'ai chi on Quality of Life in Centrally Obese Adults with Depression"

The title now reads:

The Effect of Tai Chi on Quality of Life in Centrally Obese Adults with Depression

Similarly, all instances of " $t$ 'ai chi" have been corrected to "Tai Chi" throughout the text.

The online version of this article has been corrected to reflect these changes. 